\title{
Highlights and hot topics in the management of COPD: where are we heading?
}

This article was published in the following Dove Press journal:

International Journal of COPD

18 February 2016

Number of times this article has been viewed

\section{Alvar Agustí \\ Paul W Jones ${ }^{2}$ \\ Claus Vogelmeier ${ }^{3}$}

'Thorax Institute, Hospital Clinic, University of Barcelona, Barcelona, Spain; ${ }^{2}$ Division of Clinical Science, St George's, University of London, London, UK; ${ }^{3}$ Department for Pulmonary Medicine, PhilippsUniversity of Marburg, Marburg, Germany
Correspondence: Alvar Agustí Thorax Institute, Hospital Clinic, Villarroel I70, Barcelona 08036, Spain $\mathrm{Tel}+3493227$ I70।

Fax+34932279868

Email alvar.agusti@clinic.ub.es

\section{Proceedings of the First World Lung Disease Summit, Lisbon, Portugal, November 2013}

The First World Lung Disease Summit took place in Lisbon over two days in November 2013. This inaugural meeting, of what is hoped to be a long-running annual series, brought together experts in respiratory medicine to explore many of the issues and challenges faced by clinicians when managing lung diseases, particularly asthma and COPD. The aim of the series is to present and discuss innovative science through a scientifically balanced program, and to explore how recent developments can inform clinical practice and improve patient care. The program for the inaugural meeting emphasized ongoing work in basic, clinical, and translational science as it evolves to bring about a more complete understanding of the pathology of asthma and COPD. The overall goal of the meeting was to provide delegates with insights into treatment approaches, with the aim of improving patient outcomes. This was an interactive symposium with opportunities for the delegates to express their opinions and practices and to learn how their peers manage lung diseases. The meeting program comprised three modules, each with four presenters, and explored three specific aspects of lung disease: the diagnosis and assessment of COPD, the patient perspective, and exacerbations in COPD. The presenters of each module have summarized their presentations in the three articles that comprise this special issue.

The first module covered the challenges associated with obtaining an accurate diagnosis and assessment of COPD, which are necessary to inform subsequent management of the disease. As summarized by Lange et al, this session covered the differentiation and overlap of COPD and asthma, and the use of diagnostic procedures beyond the standard spirometric measurements to ensure a sound diagnosis. The heterogeneity of COPD and the search to identify subpopulations, or phenotypes, that share certain disease characteristics predicting response to specific treatment strategies were also discussed. As reported by Jones et al, in module 2 the speakers considered the patient's perspective of COPD. This included discussion of the tools available to assess disease impact on a patient's daily life, the role of physical activity in COPD (both in terms of prognosis and rehabilitation), and the influence of comorbidities. Treatment-related factors such as choice of inhaler device and combination therapies for COPD were also covered. Finally, in module 3 the focus of the presentations moved to exacerbations in COPD. As Pavord et al report, this included the impact of exacerbations, the heterogeneity of the factors triggering them, and the complexity of identifying the most submit your manuscript | www.dovepress.com Dovepress http://dx.doi.org/10.2147/COPD.S85975
International Journal of COPD 2016:I I (Special Issue Ist World Lung Disease Summit) I-2

(c) (i) (5) 2016 Agusti et al. This work is published by Dove Medical Press Limited, and licensed under Creative Commons Attribution - Non Commercial (unported, v3.0) cc. License. The full terms of the License are available at http://creativecommons.org/licenses/by-nc/3.0/. Non-commercial uses of the work are permitted without any further permission from Dove Medical Press Limited, provided the work is properly attributed. Permissions beyond the scope of the License are administered by Dove Medical Press Limited. Information on how to request permission may be found at: http://www.dovepress.com/permissions.php 
appropriate therapy. The audience heard that, as in COPD more generally, patterns of exacerbations are emerging and that the search is on for common factors, including biomarkers, to guide treatment decisions.

During the First World Lung Disease Summit, we were given an insight into the ideas and thoughts guiding current research in respiratory medicine, allowing us a glimpse of what may come. The aim of this special issue is to share that knowledge and insight, in order to inform and inspire a wider audience with an interest in respiratory medicine.

\section{Disclosure}

AA has previously received honoraria for speaking and consultancy from Almirall, AstraZeneca, Boehringer Ingelheim, GlaxoSmithKline, MSD, Novartis, and Takeda, and has received research grants from AstraZeneca, Boehringer Ingelheim, and GlaxoSmithKline.

PJ has previously received speaker fees and has served on advisory boards for Almirall, AstraZeneca, GlaxoSmithKline, Novartis, and Pearl. All fees were contracted via his institution.

CV has previously received fees or honoraria for speaking or consultancy from Almirall, AstraZeneca, Boehringer Ingelheim, Chiesi, GlaxoSmithKline, Grifols, Mundipharma, Novartis, and Takeda, and has received research grants from Grifols.

Medical writing support was provided by David Finch on behalf of Complete Medical Communications, funded by Almirall, S.A., Barcelona, Spain.

\section{Publish your work in this journal}

The International Journal of COPD is an international, peer-reviewed journal of therapeutics and pharmacology focusing on concise rapid reporting of clinical studies and reviews in COPD. Special focus is given to the pathophysiological processes underlying the disease, intervention programs, patient focused education, and self management protocols.
This journal is indexed on PubMed Central, MedLine and CAS. The manuscript management system is completely online and includes a very quick and fair peer-review system, which is all easy to use. Visit http://www.dovepress.com/testimonials.php to read real quotes from published authors. 